\title{
Noble Interactions between Ar and Carbons
}

\author{
Mitsunori Furuya, Ayaka Yanagitsuru, Kenji Ichimura \\ Graduate School of Science and Technology, Kumamoto University, Kumamoto, Japan \\ Email: ichimura@kumamoto-u.ac.jp
}

Received May 10, 2013; revised June 10, 2013; accepted July 10, 2013

Copyright (C) 2013 Mitsunori Furuya et al. This is an open access article distributed under the Creative Commons Attribution License, which permits unrestricted use, distribution, and reproduction in any medium, provided the original work is properly cited.

\begin{abstract}
Noble interactions between Ar and carbons are observed for carbons, such as carbon nanotubes and carbon blacks by means of mass-analyzed thermal desorption. The absorption states exist at around $300 \mathrm{~K}$ as well as at around $100 \mathrm{~K}$. $\mathrm{X}$-ray photoelectron spectroscopy reveals that Ar2p shows the chemical shifts. These results suggest that Ar is in charge and it is in valence state, or gives the evidence of the chemical interaction.
\end{abstract}

Keywords: Ar; Interaction; Carbon; Valence States

\section{Introduction}

The compounds of rare gas elements such as $\mathrm{Kr}$ and $\mathrm{Xe}$ have been reported [1-5].

The examinations of compressibility for $\mathrm{C}_{60}$ using $\mathrm{He}$, $\mathrm{Ne}$ and $\mathrm{Ar}$ as pressure media and the study of diffusion kinetics in solid $\mathrm{C}_{60}$ have been carried out under the conditions of high pressure at around several kbar [6-9]. In these, the chemical interactions have not been discussed.

We have reported the chemical interactions of rare gases [10], such as He, Ne and Ar, in solid carbon nanotubes. Closed carbon nanotubes (CNTs) show larger amounts of absorption for gases such as hydrogen, He, $\mathrm{Ne}$ and Ar than opened CNTs. From these results, we conclude that sites that are preferentially found in endcaps provide more active electronic states for the chemical interaction between rare gases and solid carbon nanotubes.

This paper presents results on the thermal desorption from carbon blacks and the X-ray photoelectron spectra of Ar2p.

\section{Experimental}

$\mathrm{C}_{60}$ (Hoechst, 99.98\% purity) was used without further purification.

Endcaps and endcaps-opened multi wall carbon nanotubes (CMWCNT and OMWCNT, Bucky USA BU-200 and 201, 3 - 10 multi-layer with 2 - $10 \mathrm{~nm}$ diameter and 3 - $30 \mu \mathrm{m}$ length), endcaps and endcaps-opened single wall carbon nanotubes (CSWCNT and OSWCNT, Bucky USA BU-202 and 203, 1.4 - $3 \mathrm{~nm}$ diameter and $10-50$ $\mu \mathrm{m}$ length) were used without further purification. As for the single and multi-wall carbon nanotubes, there is the only difference in the both end structure, and the another structure is the same.

Carbon black (Seast 3HAF (S3)) and graphitized carbon blacks $(3855,3845$ and 3800) were supplied from Tokai Carbon Co. Table 1 shows the characterizaion of samples.

After vacuum heating at $653 \mathrm{~K}$ or $1073 \mathrm{~K}$, samples were exposed to Ar (Nippon Sanso, $>99.99 \%$ purity) of 1 to $1.4 \mathrm{~atm}$, at $473 \mathrm{~K}$ for 1 to 10 days. After the sample wascooled to liquid nitrogen temperature, the sample tube was evacuated to ultra-high vacuum. In-situ measurements of the thermal desorption with the temperature-rise rate of $5 \mathrm{~K} / \mathrm{min}$ and X-ray photoelectron spectra by using $\operatorname{MgK} \alpha$ were carried out.

\section{Results and Discussion}

Figures 1 and 2 show the thermal desorption of Ar from carbon blacks.

The Ar desorption peaks were observed at around 90 $100 \mathrm{~K}$ in the lower temperature region for all carbon blacks. These peak temperatures were higher than that of boiling point of Ar such as $87 \mathrm{~K}$. Therefore, these results

Table 1. Characteristics of carbon blacks.

\begin{tabular}{ccc}
\hline Sample & Particle radii $/ \mathrm{nm}$ & $\begin{array}{c}\mathrm{N}_{2} \text { specific surface } \\
\text { area } / \mathrm{m}^{2} / \mathrm{g}\end{array}$ \\
\hline Seast 3HAF (S3) & 28 & 79 \\
3855 & 25 & 90 \\
3845 & 40 & 57 \\
3800 & 70 & 27 \\
\hline
\end{tabular}




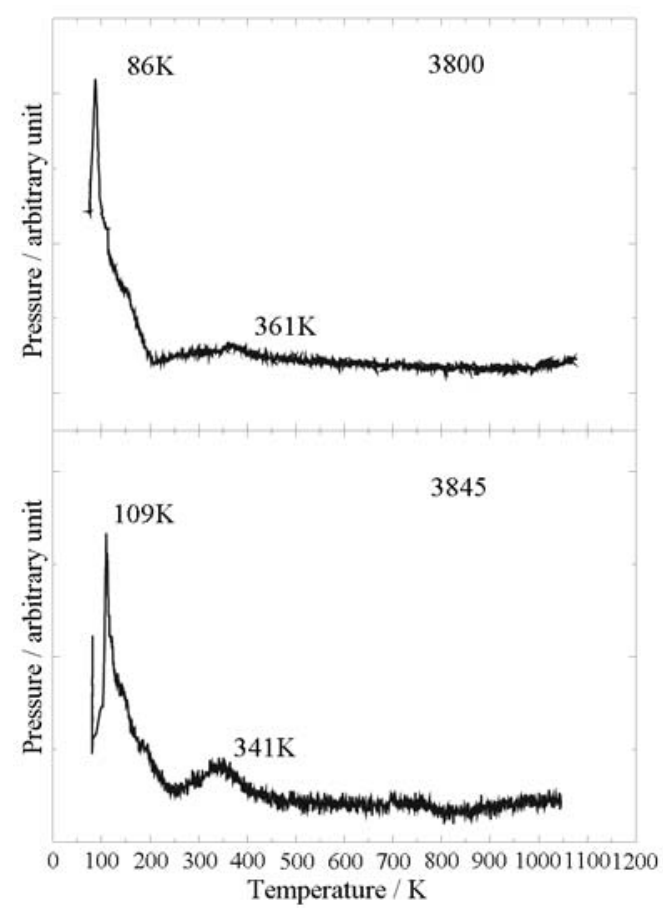

Figure 1. Thermal desorption of Ar from carbon blacks, 3800 and 3845.

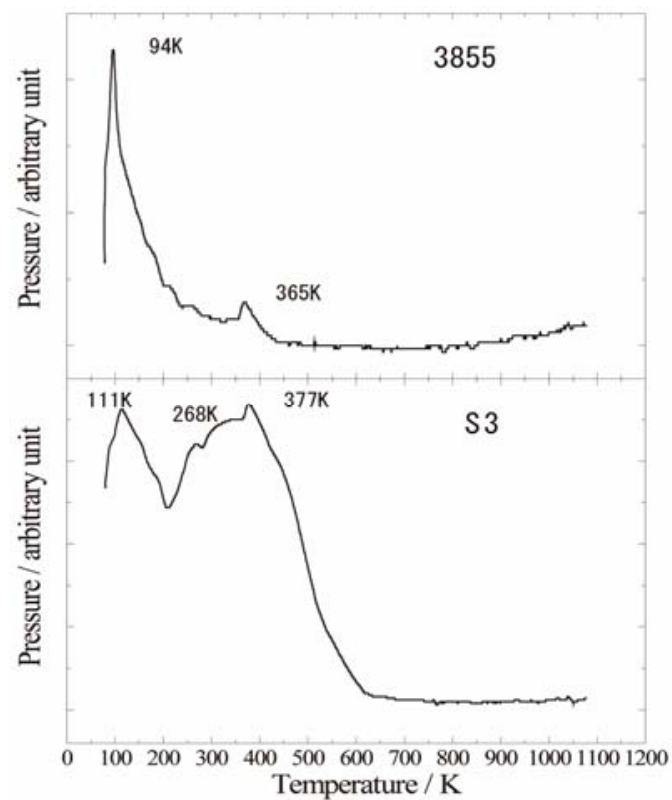

Figure 2. Thermal desorption of Ar from carbon blacks, 3855 and S3.

suggest the stronger interaction than van der Waals interaction.

In addition, the Ar desorption peaks were observed at around $350 \mathrm{~K}$ in the higher temperature region than room temperature. Therefore, these results suggest the chemical interaction between Ar and carbon blacks.

Figure 3 shows the X-ray photoelectron spectra of

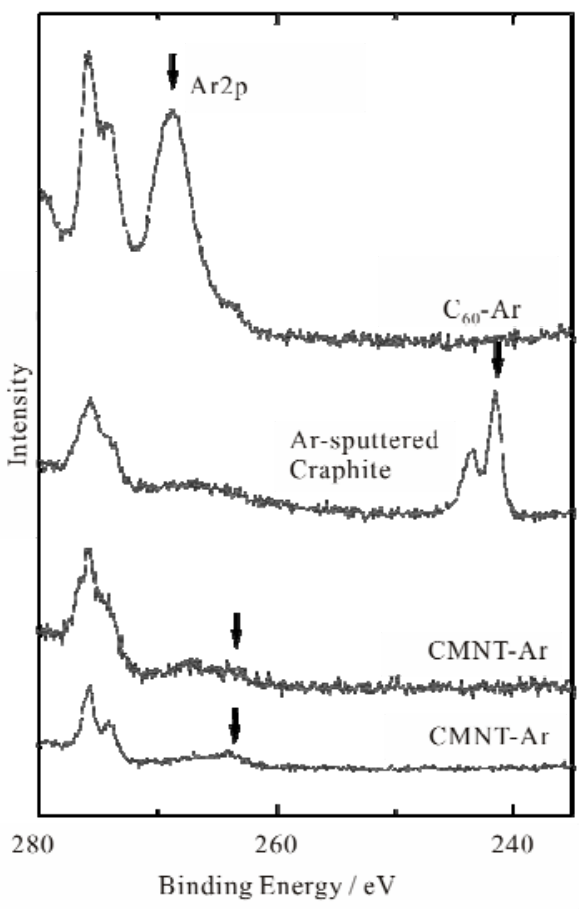

Figure 3. The $x$-ray photoelectron spectra of Ar2p for $\mathbf{C}_{60}$, graphite and closed and open multiwall carbon nanotubes.

Ar2p for $\mathrm{C}_{60}$ and closed and open multiwall carbon nanotubes exposed to Ar gas at around room temperature, and the $\mathrm{Ar}^{+}$-sputtered graphite.

The peaks appeared at around $275 \mathrm{eV}$ are assigned to the peaks due to the X-ray impurities.

For $\mathrm{Ar}^{+}$-sputtered graphite, $\mathrm{Ar} 2 \mathrm{p}_{1 / 2}-\mathrm{Ar} 2 \mathrm{p}_{3 / 2}$ peaks were observed. This spin-orbit interaction indicates that $\mathrm{Ar}$ exists as the neutral molecule in the graphite. On the other hand, for $\mathrm{C}_{60}, \mathrm{Ar} 2 \mathrm{p}$ peak was not observed at around 241 $\mathrm{eV}$ and the peak appears at around $269 \mathrm{eV}$, showing the large chemical shift to that for the $\mathrm{Ar}^{+}$-sputtered graphite at around $241 \mathrm{eV}$. The spin-orbit interaction was also not observed.

For the closed and open multiwall carbon nanotubes, although the signal intensities were weak, Ar2p peaks were observed at around $264 \mathrm{eV}$, showing also the large chemical shift to that for the $\mathrm{Ar}^{+}$-sputtered graphite at around $241 \mathrm{eV}$.

Figure 4 shows the X-ray photoelectron spectra of $\mathrm{Ar} 2 \mathrm{p}$ for the $\mathrm{Ar}^{+}$-sputtered carbon blacks. Although characteristics of the thermal desorption were different from amorphous-type carbon black and graphitized carbon blacks, the Ar2p peaks were observed at around 242 and $244 \mathrm{eV}$. The spin-orbit interaction was observed for the all spectra.

For the $\mathrm{Ar}^{+}$-sputtered graphite, the difference between $\mathrm{C} 1 \mathrm{~s}$ and $\mathrm{Ar} 2 \mathrm{p}_{3 / 2}$ was observed as $43.3 \mathrm{eV}$, and the splitting width of the spin-orbit interaction was $2.2 \mathrm{eV}$. For carbon blacks, the difference between $\mathrm{C} 1 \mathrm{~s}$ and $\mathrm{Ar} 2 \mathrm{p}_{3 / 2}$ 

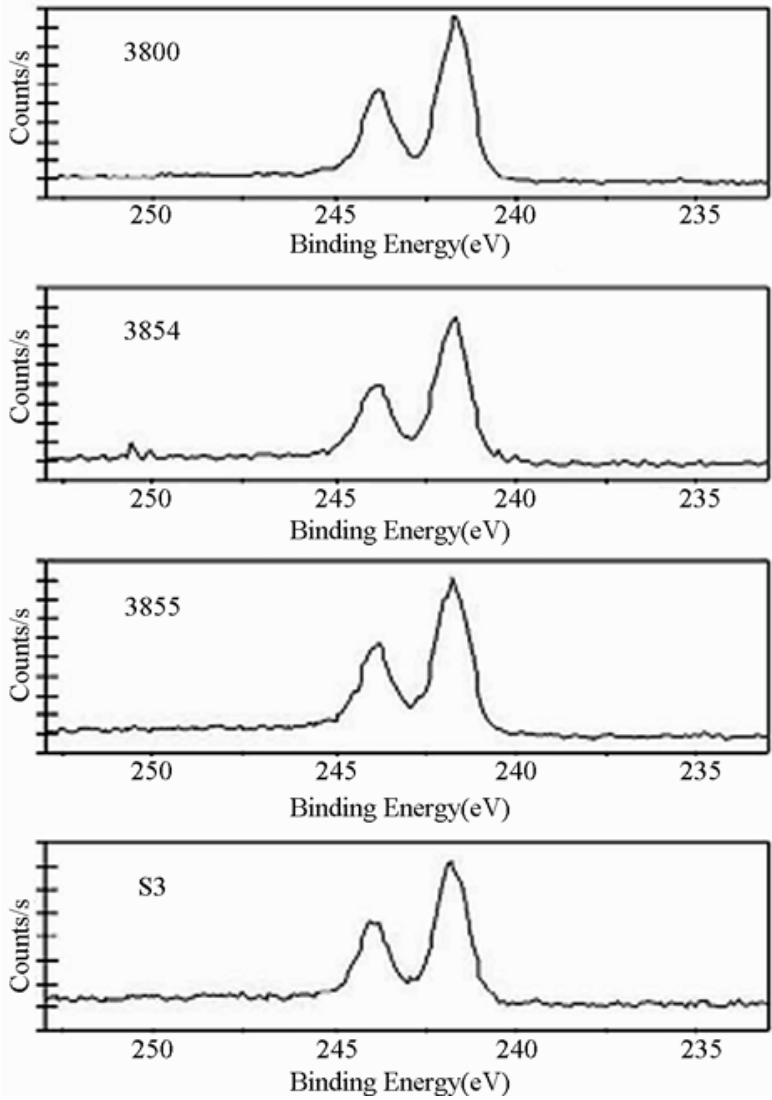

Figure 4. The X-ray photoelectron spectra of Ar2p for carbon blacks.

was observed as $42.6 \pm 0.1 \mathrm{eV}$, and the splitting width of the spin-orbit interaction was $3.0 \mathrm{eV}$. By the comparison with the $\mathrm{Ar}^{+}$-sputtered graphite, the difference between $\mathrm{C} 1 \mathrm{~s}$ and $\mathrm{Ar} 2 \mathrm{p}_{3 / 2}$ became to be lower and the splitting width of the spin-orbit interaction increased for the carbon blacks. These results indicate that the ad-/ab-sorption states observed at around $90-100 \mathrm{~K}$ and $350 \mathrm{~K}$ are due to the weak and strong chemical interactions.

\section{Conclusions}

Carbons show the noble interaction with Ar due to the characteristic structures and those electronic states. The $\mathrm{X}$-ray photoelectron spectroscopy results in the chemical interaction between $\mathrm{Ar}$ and carbons such as $\mathrm{C}_{60}$, CNTs, and carbon blacks. Carbons have possibilities of the diversity of chemical interactions with designs of structure and those electronic states.

\section{Acknowledgements}

Authors thank Tokai Carbon Co. for the sample supply of the carbon blacks. Authors also acknowledge Professor M. Koinuma of Kumamoto University for the support of XPS measurements for the $\mathrm{Ar}^{+}$-sputtered carbon blacks.

\section{REFERENCES}

[1] S. R. Gunn, "Heat of Formation of Krypton Difluoride," The Journal of Physical Chemistry, Vol. 71, No. 9, 1967, pp. 2934-2937.

doi:10.1021/j100868a025

[2] L. V. Streng and A. G. Streng, "Formation of Xenon Difluoride from Xenon and Oxygen Difluoride or Fluorine in Pyrex Glass at Room Temperature," Inorganic Chemistry, Vol. 4, No. 9, 1965, pp. 1370-1371. doi:10.1021/ic50031a035

[3] H. H. Claassen, H. Selig and J. G. Malm, "Xenon Tetrafluoride," Journal of the American Chemical Society, Vol. 84, No. 18, 1962, pp. 3593-3593. doi:10.1021/ja00877a042

[4] R. D. Burbank and G. R. Jones, "Structure of the Cubic Phase of Xenon Hexafluoride at 193.deg.K," Journal of the American Chemical Society, Vol. 96, No. 1, 1974, pp. 43-48.

[5] J. L. Huston, "Xenon Dioxide Difluoride: Isolation and Some Properties," The Journal of Physical Chemistry, Vol. 71, No. 10, 1967, pp. 3339-3341.

[6] B. Morosin, Z.-B. Hu, J. D. Jorgensen, S. Short, J. E. Schirber and G. H. Kwei, "Ne Intercalated $\mathrm{C}_{60}$ : Diffusion Kinetics," Physical Review B, Vol. 59, No. 9, 1999, pp. 6051-6057. doi:10.1103/PhysRevB.59.6051

[7] B. Morosin, J. D. Jorgensen, S. Short, G. H. Kwei and J. E. Schirber, "Ne-Intercalated $\mathrm{C}_{60}$ : Pressure Dependence of Ne-Site Occupancies," Physical Review B, Vol. 53, No. 3, 1996, pp. 1675-1678. doi:10.1103/PhysRevB.53.1675

[8] J. E. Schirber, G. H. Kwei, J. D. Jorgensen, R. L. Hitterman and B. Morosin, "Room-Temperature Compressibility of $\mathrm{C}_{60}$ : Intercalation Effects with $\mathrm{He}, \mathrm{Ne}$, and Ar," Physical Review B, Vol. 51, No. 17, 1995, pp. 1201412017. doi:10.1103/PhysRevB.51.12014

[9] G. A. Samara, L. V. Hansen, R. A. Assink, B. Morosin, J. E. Schirber and D. Loy, "Effects of Pressure and Ambient Species on the Orientational Ordering in Solid $\mathrm{C}_{60}$," Physical Review B, Vol. 47, No. 8, 1993, pp. 4756-4764. doi:10.1103/PhysRevB.47.4756

[10] K. Ichimura, K. Imaeda, C.-W. Jin and H. Inokuchi, "Super van der Waals Interaction of Fullerenes and Carbon Nanotubes with Rare Gases and Hydrogen-Storage Characteristics," Physica B: Condensed Matter, Vol. 323, No. $1-4,2002$, pp.137-139, and references in there. doi:10.1016/S0921-4526(02)00879-7 